\title{
PPIUCD: awareness and reasons for non-acceptance
}

\author{
Anila Tresa Alukal, Resmy C. Raveendran*, Lissiamma George
}

Department of Obstetrics and Gynecology, Government Medical College, Thrissur, Kerala, India

Received: 22 November 2017

Accepted: 22 December 2017

\section{*Correspondence:}

Dr. Resmy C. Raveendran,

E-mail: drresmy@gmail.com

Copyright: ( $)$ the author(s), publisher and licensee Medip Academy. This is an open-access article distributed under the terms of the Creative Commons Attribution Non-Commercial License, which permits unrestricted non-commercial use, distribution, and reproduction in any medium, provided the original work is properly cited.

\section{ABSTRACT}

Background: The recommended interval between pregnancies is at least 24 months in order to reduce the risk of adverse maternal, perinatal and infant outcomes. Ministry of Health \& Family Welfare, Government of India has taken initiative for provision of IUCD in immediate postpartum period. Several training programs and awareness camps are conducted by NHM for health service providers and also for the public. The aim of the study was to determine proportion of women accepting post placental intrauterine Contraceptive Device insertion, and to describe the factors associated with acceptability and non-acceptance.

Methods: The study was conducted at the Government Medical College Thrissur, Kerala, India and study period was 1 year (2014-2015). The study population included women who planned to deliver at Government Medical College, Thrissur during the study period including vaginal and caesarean section.

Results: The awareness regarding PPIUCD was only $11.1 \%$ whereas for interval IUCD it was $94.9 \%$. The acceptance rate of PPIUCD was very low (10.5\%). The most common reason to accept was its long action (68.5\%) The most common reason for rejection was that they wanted permanent sterilisation. The other reasons for non-acceptance include unwillingness of husband, fear of complications etc.

Conclusions: The acceptance rate was very low even though majority of the study population were well educated. The most common reason for acceptance was long action followed by reversibility. The reasons for refusal like unwillingness of husband, fear of complications etc. can be overcome by proper counselling and public awareness programs.

Keywords: Acceptance, Copper-T, Family planning, Post placental

\section{INTRODUCTION}

India is the second most populous country in the world, and accounts for more than $20 \%$ of global maternal and child deaths most of them preventable. ${ }^{1}$ Indian women have more children than desired and often too close together. Family Planning can have a positive impact on population growth, maternal mortality, and infant and new-born outcomes. ${ }^{2}$

In spite of availability of wide range of contraceptives, the unmet need for family planning is estimated to be
$12.8 \% .^{3}$ The recommended interval before attempting the next pregnancy is at least 24 months in order to reduce the risk of adverse maternal, perinatal and infant outcomes. ${ }^{4}$ Thus, by limiting births, preventing closely spaced births or births to very young or old mothers, neonatal and infant, child and maternal mortality can be reduced. ${ }^{5}$

Among the various method of family planning available for a woman, insertion of post placental Intrauterine Contraceptive Device appears appealing for several reasons: commencement of ovulation is unpredictable 
after delivery, women wish to avoid pregnancy ,but still may not be using any form of contraception, delivery may be the only time when a healthy women comes in contact with health care providers and the woman is likely to be highly motivated for accepting contraception during postpartum. ${ }^{6}$ PPIUCD is a long term and reversible method, with low expulsion rate when inserted by proper technique, cost effective, safe and feasible for inserting immediately after child birth. ${ }^{7}$ It was observed that the expulsion rate is lowest when the Intrauterine Contraceptive Deviceis inserted within 10 minutes of delivery. The woman is also less likely to notice the initial slight bleeding and cramping caused by the Intrauterine Contraceptive Device. ${ }^{8}$ Follow up can be done at 4 to 6 weeks postpartum to reinforce counselling and answer any questions. ${ }^{9}$

Despite making contraception widely available, there is poor acceptance of contraceptive methods either because of ignorance or fear of associated complications. Inadequate knowledge about contraceptive methods and incomplete or erroneous information about their use or where to procure them are the main reasons for not accepting family planning. ${ }^{10}$

Providing quality contraception methods to women is one of the cornerstones for achieving millennium development goals of improved maternal and child health. ${ }^{11}$ Accordingly Ministry of Health and Family Welfare, Government of India has taken initiative for provision of IUCD in immediate postpartum period in 2010 in collaboration with Jhpiego, India. ${ }^{12}$ Several training programs and awareness camps are conducted by NHM for health service providers and also for the public. ${ }^{13}$

Objectives of the study was to determine proportion of women accepting post placental Intrauterine Contraceptive Device insertion and to describe the factors associated with acceptability of post placental insertion in women according to their socio-demographic and obstetrics characteristics, previous contraceptive use and future pregnancy desires and also the reasons for nonacceptance.

\section{METHODS}

The study was a prospective cohort study looking at awareness, acceptance and reasons for non-acceptance of post placental Intrauterine Contraceptive Device use in women after delivery. It was conducted at the Government Medical College Thrissur, Kerala, a tertiary referral centre. Duration of the study was 1 year, from February 2014 to January 2015, after getting clearance from Institutional Research Committee and ethical committee. The study population included women who delivered at Govt. Medical College, Thrissur during the study period both vaginal and caesarean section. Sample size was 514. All women coming for delivery were counselled regarding different family planning methods, advantages and disadvantages of Post placental Intrauterine Contraceptive Device. A questionnaire was filled up to assess their knowledge, attitude and acceptability of various family planning methods. Reasons for refusal if any were also being documented. In patients who accept postplacental Intrauterine Contraceptive Device as a method of family planning, a written informed consent was taken, and it was marked on top of their case sheets. CuT is inserted within 10 minutes of placental separation in females with vaginal delivery and caesarean section who gave prior consent.

Data was coded and entered in MS Excel and analysed using SPSS software.

\section{RESULTS}

Most of the subjects (78.3\%) of the study belonged to the age group of 21-30years (Table 1). Most subjects of the study population had completed high school education (74.2\%) showing that the literacy rate in Kerala is high (Table 2).

Table 1: Age distribution of the study population.

\begin{tabular}{|lll|}
\hline Age group & No. of women, $\mathrm{n=514}$ & Percentage \\
\hline Less than 20 & 43 & 8.4 \\
\hline $21-30$ & 403 & 78.4 \\
\hline $31-40$ & 64 & 12.5 \\
\hline More than 40 & 4 & .8 \\
\hline
\end{tabular}

Majority (67.6\%) of the women were housewives. Only $32.2 \%$ had some form of employment. Most of the study population belonged to multigravida group $(66.2 \%)$. Around $28.9 \%$ of them had last child birth within 3 yrs., $37.3 \%$ had last child birth 3 or more years earlier and $33.6 \%$ were primigravida.

Table 2: Distribution of educational status of the study population.

\begin{tabular}{|lll|}
\hline Education & No. of women, $\mathbf{n = 5 1 4}$ & Percentage \\
\hline Nil & 6 & 1.2 \\
\hline Primary & 59 & 11.5 \\
\hline 10th pass & 382 & 74.3 \\
\hline Graduate & 67 & 13.0 \\
\hline
\end{tabular}

\section{Awareness and prior use of contraceptive methods}

$92.6 \%$ of the women had awareness of natural methods of contraception. $96.7 \%$ women were aware of barrier contraception. $96.8 \%$ women were aware of permanent methods of sterilisation. $71.6 \%$ of the women gave history of prior use of some form of contraceptive method. $69.6 \%$ of women gave history of use of natural methods of contraception. $59.9 \%$ women of the study population gave history of use of barrier contraception. Only $19.1 \%$ had used Oral contraceptive pills for contraception and only $2.1 \%$ had used Intrauterine Contraceptive Device in the past. Only $27.4 \%$ of the 
study population had a planned pregnancy. Only $11.1 \%$ women had prior knowledge of postpartum intrauterine contraceptive device as a contraceptive method.

\section{Acceptance and reasons for nonacceptance of PPIUCD.}

The acceptance rate of post placental IUCD was only $10.5 \%$ (54 women). Majority of the acceptors of PPIUCD accounting for $68.5 \%$ among the acceptors had completed high schooleducation. Only $3.7 \%$ had no schooling. Among the acceptors 55.6\% women were employed.81.5\% of the women who accepted PPIUCD were multigravida. Acceptance of PPIUCD was more (64.8\%) among women who had their last child birth in less than 3 years and it was found to be more among women who had used some form of contraception previously.

$74.1 \%$ of women who had an unplanned pregnancy accepted PPIUCD. Only $6 \%$ of the acceptors had prior knowledge of PPIUCD. Most common reason for accepting PPIUCD was its long action.

Table 3: Reasons for accepting PPIUD among the women who consented.

\begin{tabular}{|lll|}
\hline $\begin{array}{l}\text { Reason for } \\
\text { accepting }\end{array}$ & $\begin{array}{l}\text { No. of women } \\
\mathrm{n}=54\end{array}$ & Percentage \\
\hline No side effects & 1 & 1.9 \\
\hline Long acting & 37 & 68.5 \\
\hline Reversible & 16 & 29.6 \\
\hline Total & 54 & 100.0 \\
\hline
\end{tabular}

Most common reason for acceptance of PPIUCD was the fact it is longacting $-68.5 \%$ (37 women), whereas 16 women $(29.6 \%)$ accepted it because of its reversibility (Table 3).

Table 4: Reason cited by women to reject the PPIUCD.

\begin{tabular}{|lll|}
\hline Reason to reject & $\begin{array}{l}\text { No. of } \\
\text { women } \\
\mathrm{n}=460\end{array}$ & Percentage \\
\hline Want to use other methods & 150 & 32.6 \\
\hline Want permanent sterilisation & 243 & 52.8 \\
\hline Husband not willing & 55 & 11.9 \\
\hline Afraid of complications & 13 & 2.8 \\
\hline
\end{tabular}

Among the 460 women who did not accept, majority (243 women, $52.8 \%$ ) wanted permanent method of sterilisation, 150 women $(32.6 \%)$ wanted other methods, while the spouse was not willing in 55 cases $(11.9 \%)$. Thirteen women $(2.8 \%)$ were afraid of the complications (Table 4).

In present study there was significant difference (value 0.000) in the acceptance of PPIUCD among housewives and employed women. The acceptance was found to be more in employed women. When comparing the acceptance of PPIUCD among primigravida and multigravida it was found that the acceptance was more among multigravida and the difference was statistically significant ( $p$ value 0.007 ). No significant difference was noted in the acceptance of PPIUCD among those who had awareness regarding IUCD as a contraceptive device and those who had no awareness. There was no significant difference in the acceptance of PPIUCD among those who had prior use of some form of contraception and those with no prior use of contraception. There was no significant association between the acceptance of PPIUCD and prior use of IUCD. The acceptance of PPIUCD as a method of contraception was more in those who had an unplanned pregnancy. But the difference was not statistically significant. There was no significant difference between the acceptance of PPIUCD among those who had heard of it before and those who had not. In our study significant difference was found in the acceptance of PPIUCD among those who had passed 10thstandard when compared to those who had not. Even though the acceptance of PPIUCD was more among women below the age of 30 , the difference was not statistically significant.

Table 5: Distribution of other preferred method among the study population.

\begin{tabular}{|l|l|l|}
\hline $\begin{array}{l}\text { Other preferred } \\
\text { method }\end{array}$ & $\begin{array}{l}\text { No. of women } \\
\mathbf{n = 4 6 0}\end{array}$ & Percentage \\
\hline Natural & 150 & 32.6 \\
\hline Barrier & 243 & 52.8 \\
\hline OC pill & 55 & 11.9 \\
\hline IUCD & 13 & 2.8 \\
\hline
\end{tabular}

\section{DISCUSSION}

In present study the awareness of 514 patients regarding contraception and PPIUCD were assessed. In present study the acceptance of PPIUCD was $10.5 \%$. In a study by Kanhere AV et al the acceptance rate was $36 \% .{ }^{14}$ The acceptance rate of PPIUCD in present study was very low even though majority of the study population were educated and well aware about contraceptive methods. Their prior awareness regarding PPIUCD was also very low.

The mean age of the study population was 26.12. The minimum age was 18 and maximum age was 42 . Majority of the study population belonged to the age group of 21-30 i.e. $78.4 \%$. This is in concordance with a similar study conducted by Singal et al in which the mean age was $23.12 .{ }^{15}$ In present study population majority of the acceptors of PPIUCD belonged to the age group 21$30(75.9 \%)$. This was comparable to a similar study conducted by Katheit et al which had maximum acceptance in the age group 21-30 (78.3\%). ${ }^{16}$

In present study majority of the study population had passed tenth standard $87.3 \%$. Only 6 out of 514 (1.2) had 
no schooling. Around $13 \%$ were graduates. Among the acceptors of PPIUCD majority had secondary education $81.5 \%$ and $28.5 \%$ had no secondary education. The acceptance of PPIUCD was more among those women who had passed $10^{\text {th }}$ standard and the association were statistically significant with a $\mathrm{p}$ value of 0.034 . In a similar study by Katheit et al it was found that the acceptance was more among those who were literate $(65 \%) .{ }^{16}$

In present study, majority of the subjects were housewives $(67.7 \%)$. Only $32.3 \%$ were employed. The acceptance of PPIUCD was more among those who were employed $55.6 \%$ and the difference was statistically significant.

In present study majority of the women were multigravida (65.2\%). In the acceptors of PPIUCD 81.5 $\%$ were multigravida and $18.5 \%$ were primigravida and the difference was statistically significant. In a similar study conducted by Qureshi et al, among acceptors of PPIUCD $68.3 \%$ were multiparous and $33.6 \%$ were primiparous. $^{2}$ In a study by Katheit et al the acceptance in multigravida was $70.6 \%$ and in primi para were $29.6 \% .^{16}$

In present study $71.6 \%$ of the population gave history of prior use of contraceptive methods. In the acceptors of PPIUCD also $72.2 \%$ gave history of contraceptive use and there was no significant difference between the groups.

In present study only $11.1 \%$ of the study population had prior knowledge of PPIUCD. Among the acceptors of PPIUCD also $11.1 \%$ had prior knowledge of PPIUCD. This implies that the awareness regarding PPIUCD is very low and more publicity campaigns and programs should be introduced to increase awareness and thus acceptance of PPIUCD.

In present study, most common reason cited to refuse PPIUCD was that most multigravida who had two children requested for permanent sterilisation $(52.8 \%)$. The other reasons being want to use other methods $(32.6 \%)$, husband not willing $(11.9 \%)$ and afraid of complications $(2.8 \%)$. In a similar study by Kanhere AV et al the reasons for declining were wanted permanent sterilisation $(20 \%)$, wanted other methods of contraception $(32 \%)$ and family pressure $(9 \%) .{ }^{14}$

In present study the other preferred method being barrier method for $52.8 \%$ followed by natural method $32.6 \%$ and least preferred being IUCD (2.8\%). In the study by Kanhere AV et al the other preferred method was barrier $(47 \%)$ followed by natural method (19\%) and IUCD $(13 \%) .{ }^{14}$

In present study the most common reason to accept was its long action (68.5\%) reversible (29.6\%). In a similar study by Kanhere AV et al, the main reason accept was its long action (28\%), fewer follow up visit (20\%), reversible $(17 \%){ }^{14}$

In present study the awareness regarding PPIUCD was only $11.1 \%$ whereas for interval IUCD it was $94.9 \%$. In a similar study conducted by Katheit et al in Bhopal it was found that the awareness regarding PPIUCD was $5.9 \%$ and interval IUCD was $73.5 \% .^{16}$ This implies that the awareness of present study population regarding contraceptives is more when compared to other states. But the awareness regarding PPIUCD is still less and the awareness has to be increased in order to increase the acceptance.

\section{CONCLUSION}

Even in a state like Kerala with $100 \%$ literacy, the acceptance rate was very low. This emphasises the need for proper counselling of females regarding family planning methods including IUCD and PPIUCD. The prior knowledge of PPIUCD was only $11 \%$. This should be overcome with the help of social media as well as health care workers starting from ASHA workers to consultants. The reasons for refusal like unwillingness of husband, fear of complications etc. can be overcome by proper counselling and public awareness programs.

\section{ACKNOWLEDGMENTS}

Authors would like to thank Department of Obstetrics and Gynecology, Thrissur, for their cooperation extended throughout this study.

Funding: No funding sources

Conflict of interest: None declared

Ethical approval: The study was approved by the Institutional Ethics Committee

\section{REFERENCES}

1. Lucksom PG, Kanungo BK, Sebastian N, Mehrotra R, Pradhan D, Upadhya R. Comparative study of interval versus postpartum $\mathrm{Cu}-\mathrm{T}$ insertion in a central referral hospital of North East India. Int J Reprod Contracept Obstet Gynecol. 2015 Feb;4(1):47-51.

2. Shukla M, Qureshi S, Chandrawati. Post placental intrauterine device insertion a five year experience at a tertiary care centre in north India. Indian $\mathbf{J}$ Med Res. 2012;136(3):432-5.

3. Deshpande S, Gadappa S, Yelikar K, Wanjare N, Andurkar S. Awareness, acceptability and clinical outcome of post-placental insertion of intrauterine contraceptive device in Marathwada region, India. Indian J Obstet Gynecol Res. 2017;4(1):77-82.

4. Nisha S, Sathi MS, Vijayan CP. Post-placental insertion of IUCD in a tertiary care centre Acceptance and safety. J Evol Med Dent Sci. 2016;5(80):5933-8.

5. Kathpalia SK, Mustafa MS. Awareness about Postpartum insertion of intrauterine device among 
antenatal cases. Med J Armed Forces India. 2015;71:221-4.

6. Bai Gujju RL, Prasad U, Prasad U. Study on the acceptance, complications, and continuation rate of postpartum family planning using the post placental intrauterine contraceptive device among women delivering at a tertiary care hospital. Int J Reprod Contracept Obstet Gynecol. 2015;4:388-91.

7. Bedi PK, Guliani MS, Bala S. A prospective study to assess the safety and expulsion rate of copper T380A in immediate post-partum period during caesarean section. Int J Reprod Contracept Obstet Gynecol. 2016 Sept;5(9):3195-9.

8. Yadav S, Joshi R, Solanki M. Knowledge attitude practice and acceptance of postpartum intrauterine devices among postpartal women in a tertiary care center. Int J Reprod Contracept Obstet Gynecol. 2017 Apr;6(4):1507-10.

9. Kumar S, Sethi R, Balasubramaniam S, Charurat E, Lalchandani K, Semba R, et al. Women's experience with postpartum intrauterine contraceptive device use in India. Reprod Health. 2014;11:32.

10. Gautam R, Arya KN, Kharakwal S, Singh S, Trivedi M. Overview of immediate PPIUCD application in Bundelkhand Region. J Evol Med Dental Sci. 2014;3:9518-26.

11. Mishra S. Evaluation of safety, efficacy, and expulsion of post-placental and intracesarean insertion of intrauterine contraceptive device (PPIUCD). J Obstet Gynaecol India. 2014;64:337.
12. Postpartum IUCD Facilitators' Guide November, 2010 Family Planning Division Ministry of Health and Family Welfare, Government of India. Available at

http://www.ukhfws.org/uploads/documents/doc_947 9_ppiucd-facilitators-guide-feb-2011-final.pdf

13. Gadre SS, Ahirwar R. Level of acceptance of IUCD insertion in Indian women - a cross-sectional mixed research from central India. Int J Reprod Contracept Obstet Gynecol. 2015;4(4):1079-85.

14. Kanhere AV, Pateriya P, Jain M. Acceptability and feasibility of immediate postpartum IUCD insertion in a tertiary care centre in Central India. Int J Reprod Contracept Obstet Gynecol. 2015;4(1):179-84.

15. Singal S, Bharti R, Dewan R. Clinical outcome of postplacental Copper $\mathrm{T}$ 380A insertion in women delivering by caesarean section. JCDR. 2014 Sep;8(9):OC01.

16. Katheit G, Agarwal J. Evaluation of post-placental intrauterine device (PPIUCD) in terms of awareness, acceptance, and expulsion in a tertiary care centre. Int $\mathrm{J}$ Reprod Contracept Obstet Gynaecol. 2013;2:539-43.

Cite this article as: Alukal AT, Raveendran RC, George L. PPIUCD: awareness and reasons for nonacceptance. Int J Reprod Contracept Obstet Gynecol 2018;7:582-6. 